\title{
Optimisation and Prediction of Fresh Ultra-High-Performance Concrete Properties Enhanced with Nanosilica
}

\author{
Khaldon Kasim Aswed ${ }^{1}$, Maan S. Hassan ${ }^{2 *}$ and Hussein Al-Quraishi ${ }^{3}$
}

\begin{abstract}
The use of high chemical admixture dosages in ultra-high-performance concrete (UHPC) mixtures to achieve adequate water demand can slow down early cement hydration and prolong the setting time. In this study, the effects of nanosilica (Ns) with high chemical admixture dosages on the rheological properties of UHPC was investigated. A factorial design approach was employed to predict and optimise the Ns content, water-binder ratio (W/B), and sand-binder $(\mathrm{s} / \mathrm{b})$ ratio to obtain the best flowability, setting time, and compressive strength. This study represents an attempt to modelling and optimise eighteen UHPC mixtures containing various proportions of water, cement, and sand, with the Ns powder as a possible property enhancer to achieve the best rheological properties. Response surface analyses revealed the significant effect of Ns in controlling the prolonged setting time and improving the compressive strength. Based on the applied criterion conditions, the optimisation results indicated two mixtures targeting either the maximum compressive strength or cost effective materials. The use of a $1.12 \mathrm{~s} / \mathrm{b}$ ratio with a controlling level of $0.8 \% \mathrm{Ns}$ content was suitable to fulfil the compressive strength, flow, and setting time limit values.
\end{abstract}

\section{Introduction}

Ultra-high-performance concrete (UHPC) is a significant outcome of various challenging techniques used to improve the concrete microstructure and maximise the packing density of different sizes of particles within concrete. Since it was invented, UHPC is characterised by a very high compressive strength exceeding $150 \mathrm{MPa}$ and other improved mechanical properties, such as tensile strength, flexural strength, ductility, and impact resistance (de Larrard and Sedran 1994; Yoo and Banthia 2016). In addition, UHPC exhibits favourable behaviour, such as high modulus of elasticity, low creep and shrinkage deformations, and high durability against different exposure conditions, namely, chloride ion penetration resistance and reinforcement corrosion resistance under extreme exposure conditions (Graybeal 2006; Dobias et al. 2016; Hassan 2018; Xie et al. 2018; Fan et al. 2019; Radhi et al. 2021). These exceptional properties can generally be achieved using the following approaches.

a. Proportioning UHPC using high binder contents, including cement, silica fume, and other pozzolanic materials, and using fine sand with a grain size distribution that typically ranges between $100 \mu \mathrm{m}$ and 1 $\mathrm{mm}$. This approach effectively refines the microstruc-

${ }^{1} \mathrm{Ph} . \mathrm{D}$ student, Civil Engineering Dept., University of Technology, 10066, Baghdad, Iraq.

${ }^{2}$ Professor, Civil Engineering Dept., University of Technology, 10066, Baghdad, Iraq. *Corresponding author, E-mail: 40018@uotechnology.edu.iq

${ }^{3}$ Professor, Civil Engineering Dept., University of Technology, 10066, Baghdad, Iraq. ture, thus enhances mechanical and durability properties.

b. Reducing the water-binder ratio to less than 0.25 (Sidodikromo et al. 2019); the ratio can be as low as 0.12 (Graybeal 2007). The result is concrete with practically no capillaries (Fehling et al. 2014; Ehsan et al. 2015).

Water reduction and finely graded mixtures are typically associated with poor workability. A workable concrete mixture is usually obtained using excessively high dosages of high range water reducing admixtures (HRWRs). HRWR contents exceeding 4\% cement content may be used (Ehsan et al. 2015; Shafieifar et al. 2017; Ghous et al. 2018). Such high HRWR levels are expected to extend the setting time of concrete, sometimes to impractical levels. Based on the penetration resistance testing method (AASHTO 2011), initial setting times from more than $1 \mathrm{~h}$ up to $15 \mathrm{~h}$ of various UHPC mixtures were recorded, and the final setting time took up to $20 \mathrm{~h}$ (Graybeal 2007; Swenty and Graybeal 2013). Camiletti et al. (2013) measured the setting times of cement paste specimens using a Vicat needle according to ASTM C191-19 (ASTM 2019). They observed high initial setting times exceeding $8 \mathrm{~h}$ for reference specimens prepared at $10^{\circ} \mathrm{C}$ and $5 \mathrm{~h}$ for those at $20^{\circ} \mathrm{C}$. However, the initial setting times decreased to approximately $2 \mathrm{~h}$ when nano- $\mathrm{NaCO}_{3}$ substituted $15 \%$ cementitious content. Casting UHPC on site may be followed by a long setting period. (Graybeal 2007). These extended setting periods may delay the framework removal, causing significant extensions in construction schedules.

The roles of nanosilica (Ns) in modifying the concrete microstructure and improving the properties of fresh and hardened concrete are well recognised 
Table 1 Chemical compositions of cement and silica fume.

\begin{tabular}{|c|c|c|c|c|c|c|c|c|c|c|}
\hline Substance & $\mathrm{CaO}$ & $\mathrm{SiO}_{2}$ & $\mathrm{Al}_{2} \mathrm{O}_{3}$ & $\mathrm{Fe}_{2} \mathrm{O}_{3}$ & $\mathrm{MgO}$ & $\mathrm{SO}_{3}$ & $\mathrm{Na}_{2} \mathrm{O}$ & $\mathrm{K}_{2} \mathrm{O}$ & LOI & Moisture \\
\hline Cement (\%) & 63.4 & 21.0 & 5.0 & 3.8 & 2.3 & 2.5 & 0.22 & 0.5 & 1.6 & - \\
\hline Silica Fume (\%) & - & 94.9 & - & - & - & 0.8 & $\begin{array}{c}0.87 \\
\left(\mathrm{Na}_{2} \mathrm{O} \text { eq. }\right)\end{array}$ & 1.75 & 0.72 \\
\hline
\end{tabular}

(Hassan et al. 2017). However, the evaluation of $\mathrm{SiO}_{2}$ nanoparticles used in producing UHPC in previous studies reflects some contradictory trends. The idea that UHPC develops a highly densified microstructure that is not likely to be further improved by the pozzolanic and filling effects of nanoparticles is a possible reason for the slight improvement of the concrete properties. Another reason is that low water contents typically used in UHPC mixes are insufficient for the complete hydration of the high cementitious contents.

The role of Ns regarding UHPC workability and water demand may also be explained in the light of packing and water film thickness theory. According to this theory, mixing water first fills in voids between solid particles while the remaining water forms a wet film with a thickness that increases the more available external water is. The wet film thickness (WFT) is assumed to be mainly related to the flowability of the fresh mixture (Ghasemi et al. 2019). When the fine content is low, the inclusion of extremely fine particles is expected to increase the packing density and reduce voids content between solid particles. This means less water is required to fill in the voids and more water film thickness and hence better flowability and workability are expected. However, with a high fine solid content like these of UHPC mixes, the continuous addition of very fine Ns particles may decrease the packing density resulting in higher water content required to fill the packing voids and lower water film thickness. The result is mixes with less workability and flowability (Kwan and McKinley 2014).

Mercury intrusion porosimetry and scanning electron microscopy images showed that the inclusion of Ns particles in UHPC with a low w/c ratio of 0.2 significantly improved the cement aggregate transitional zone, consumed more $\mathrm{Ca}(\mathrm{OH})_{2}$, densified the concrete microstructure, and increased the compressive strength (Ghafari et al. 2014). An optimal Ns content of 3\% yielded the best improvement. However, the addition of Ns considerably reduces the mixture flow (Ghafari et al. 2014). Yu et al. (2014) found that the addition of Ns particles to UHPC with a relatively low binder content (less than $500 \mathrm{~kg} / \mathrm{m}^{3}$ ) increased the compressive strength. The optimum improvement was recorded at three days, compared to seven and 28 days of curing, with the best results recorded for $4 \% \mathrm{Ns}$ (of cement weight). They also observed a significant decrease in flowability, owing to Ns particle inclusion. For instance, the flow decreased from $337 \mathrm{~mm}$ for the control mixture to $225 \mathrm{~mm}$ for the $5 \%$ Ns mixture. Another key observation is that Ns can significantly reduce the duration of the dormant period of cement hydration from an ex- tended period of $30 \mathrm{~h}$ to $10 \mathrm{~h}$. This reduction indicates that shorter setting and hardening times are expected when Ns is added. The extended times are attributed to the inclusion of excessive amounts of superplasticisers in UHPC (Yu et al. 2014). Yu's work is performed using low levels of cement content, consistent dosages of HRWR and the 28th day compressive strengths are generally less than $100 \mathrm{MPa}$. Maintaining consistent dosages of the superplasticizer is however not possible when Ns is added to UHPC mixes using typical high cement contents $\left(800\right.$ to $\left.1000 \mathrm{~kg} / \mathrm{m}^{3}\right)$ while reaching practical flowability. Ns powder with its excessively high surface area, absorbs high amounts of mixing water and hence, elevates the water requirements for the mix. If the water content is maintained to achieve the required compressive strength, additional dosages of the superplasticiser must be used to lubricate the mix particles and ensure reasonable flowability. The effect of these additional HRWR amounts in prolonging the setting time must be considered.

The objective of this study is to investigate the most significant factors that may influence the rheological characteristics of UHPC. In this study, an attempt was made to modelling and optimise UHPC mixtures containing various proportions of water, cement, and sand, with the Ns powder as a possible property enhancer. The aim of such optimisation is to determine the optimum ingredient proportions and Ns content to achieve the best rheological properties, such as flow, setting time, and HRWR requirements. The optimisation should also target the highest compressive strength as a strong indication of the overall mechanical behaviour.

\section{Experimental programme}

\subsection{Materials}

Ordinary Portland cement with a Blaine specific surface area of $3170 \mathrm{~cm}^{2} / \mathrm{g}$ was used. The physical properties and chemical composition satisfied the ASTM C150/C150M requirements (ASTM 2015a). Silica fume produced to ASTM C1240-15 (ASTM 2015b) standard, with a pozzolanic activity index of $121 \%$ and a specific surface area of $20.5 \mathrm{~m}^{2} / \mathrm{g}$, was used as a reactive powder The chemical compositions of the cement and silica fume are listed in Table 1. Ns was AEROSIL 200 product in powder form with a specific surface area of 200 $\mathrm{m}^{2} / \mathrm{g}, \mathrm{SiO}_{2}$ content of $99.9 \%, \mathrm{pH}$ of 4.1 , and specific gravity of 2.6. Hyperplast PC202 was used as a high performance polycarboxylic polymer-based HRWR; it has a specific gravity of $1.07, \mathrm{pH}$ of 6 , solid content of $42.1 \%$ and chloride free composition. The Ns powder container was kept tightly closed in a ventilated place at 
a maximum temperature of $23^{\circ} \mathrm{C}$ during storage. Measures were taken including the use of safety glasses, plastic gloves and certified respirator during the handling.

The fine quartz sand used in this study was a mix of $40 \%$ Sikadur 504 (with particles graded from $80 \mu \mathrm{m}$ to $0.2 \mathrm{~mm}$ ) and $60 \%$ Sikadur 507 (with particles graded from 0.3 to $0.85 \mathrm{~mm}$ ). The blended fine sand had a bulk density of $1500 \mathrm{~kg} / \mathrm{m}^{3}$ and a specific gravity of 2.7 . Particle size distributions of Portland cement, silica fume, Ns, quartz sand and quartz powder are shown in Fig. 1.

Straight-shaped copper coated micro-steel fibres were used. The fibre lengths ranged from 15 to $17 \mathrm{~mm}$, and the diameter was between 0.18 and $0.23 \mathrm{~mm}$ (the aspect ratios ranged from 65 to 94). The ultimate tensile strength of the steel was $2991 \mathrm{MPa}$. The fibres were used at a consistent volume dosage of $2 \%$ based on concrete volume.

\subsection{Methods and parameters}

A statistical approach was applied to optimise the parameters (water-binder ratio $\mathrm{W} / \mathrm{B}$, sand-binder ratio $\mathrm{s} / \mathrm{b}$, and Ns content) to optimise the research variables (compressive strength, flow, and setting time). A quadratic factorial design was performed using DesignExpert 12 software. The approach was also applied to derive equations for predicting the values of the research variables. The following parameters were used.

a. $\mathrm{W} / \mathrm{B}$ ratio: The $\mathrm{W} / \mathrm{B}$ ratio is a critical parameter for determining the compressive strength and rheological characteristics of concrete. The $\mathrm{W} / \mathrm{B}$ ratio ranged from 0.16 to 0.2

b. $s / b$ ratio: The $s / b$ ratio represents a cost-determining factor. Maximising this parameter reduces the UHPC unit cost. The $\mathrm{s} / \mathrm{b}$ ratio range considered in this study was 0.8 to 1.2 . c. Ns: This represents the percentage ratio of Ns powder (based on the total binder weight); the range was $0 \%$ to $4 \%$.

The total required combinations of the design parameters required to conduct the second order (quadratic) factorial regression analysis were selected using software based on the parameter limits and central composite design. This design type offers the ability to predict the response and precisely perform the surface response with a relatively minimum number of experiments (Soroushian et al. 2013; Abellán et al. 2020; Harith et al. 2021; Shishegaran et al. 2021). The number of experiments required to achieve satisfactory statistical analysis based on a quadratic regression model for each response can be determined using $2 \mathrm{k}+2 \mathrm{k}+\mathrm{c}$ (where $\mathrm{k}$ is the number of design parameters). The first term, $2 \mathrm{k}$, covers the factorial points, that is, combinations involving all possible maximum and minimum limits of the three parameters (eight end points). The second term covers the axial points at a distance $\pm \alpha$ from the origin, typically beyond the end points (six points central points). The selected values of $\mathrm{c}$ and $\alpha$ were 4 and 1.78885, respectively (Abellán et al. 2020; Náprstek et al. 2021). Therefore, the total number of required mixtures was $8+6+4=18$ mixtures.

The end, central, and axial values for each parameter were calculated and coded using Eq. (1):

$$
X_{j}=\frac{Z_{j}-Z_{0 j}}{\Delta_{j}}
$$

where $X_{j}$ and $Z_{j}$ are the coded and real values, respectively, $Z_{0 j}$ is the real value at the centre, and $\Delta$ is the difference between the central point and the lower end point.

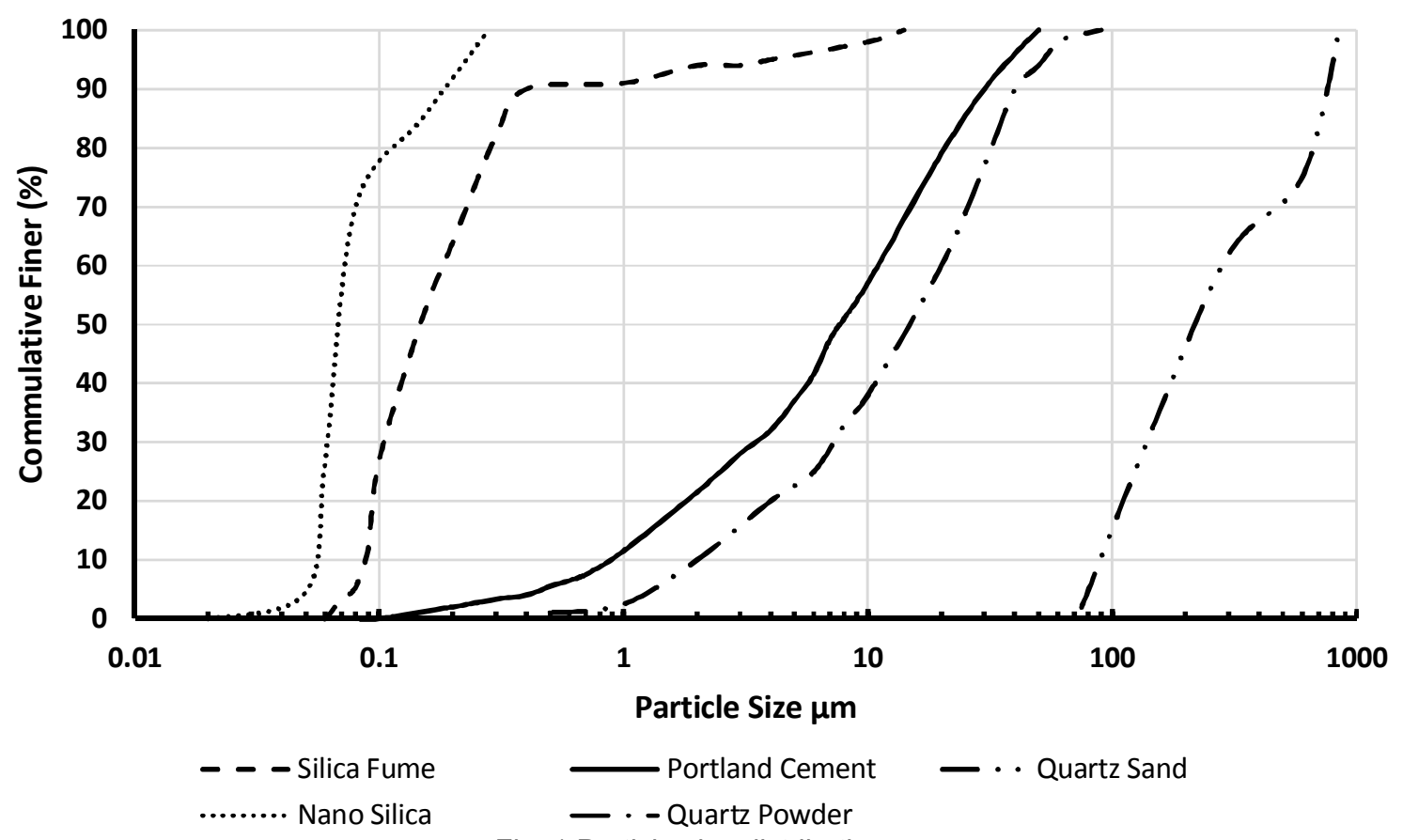

Fig. 1 Particle size distributions. 
Table 2 Real and coded values of parameters at axial, end, and central points.

\begin{tabular}{|c|c|c|c|c|c|c|}
\hline Parameter & Symbol & Axial & End & Central & End & Axial \\
\hline $\begin{array}{c}\text { Coded values } \\
\text { (all parameters) }\end{array}$ & & -1.789 & -1 & 0 & 1 & 1.789 \\
\hline W/B & A & 0.1442 & 0.16 & 0.18 & 0.2 & 0.2158 \\
\hline s/b & B & 0.6422 & 0.8 & 1 & 1.2 & 1.3578 \\
\hline $\begin{array}{c}\text { Ns } \\
\text { (\% of binder weight) }\end{array}$ & C & 0 & 0 & 2 & 4 & 5.578 \\
\hline
\end{tabular}

Table 3 Combinations of design parameters and mix proportions calculated as weight ratio of cement.

\begin{tabular}{|c|c|c|c|c|c|c|c|c|c|c|}
\hline \multirow[b]{2}{*}{ Mix } & \multicolumn{3}{|c|}{ Parameter } & \multicolumn{7}{|c|}{ Ingredient proportion } \\
\hline & $\mathrm{W} / \mathrm{B}$ & $\mathrm{s} / \mathrm{b}$ & Ns $\%$ & Cement & $\begin{array}{l}\text { Silica } \\
\text { fume }\end{array}$ & Ns & $\begin{array}{l}\text { Quartz } \\
\text { powder }\end{array}$ & Fine sand & Steel microfibres & HRWR \\
\hline 1 & 0.16 & 0.8 & 0 & 1 & 0.209 & 0 & 0.217 & 0.954 & 0.170 & 0.047 \\
\hline 2 & 0.2 & 0.8 & 0 & 1 & 0.209 & 0 & 0.217 & 0.954 & 0.170 & 0.044 \\
\hline 3 & 0.16 & 1.2 & 0 & 1 & 0.212 & 0 & 0.270 & 1.454 & 0.212 & 0.046 \\
\hline 4 & 0.2 & 1.2 & 0 & 1 & 0.212 & 0 & 0.270 & 1.454 & 0.212 & 0.044 \\
\hline 5 & 0.16 & 0.8 & 4 & 1 & 0.223 & 0.051 & 0.232 & 1.019 & 0.182 & 0.056 \\
\hline 6 & 0.2 & 0.8 & 4 & 1 & 0.223 & 0.051 & 0.232 & 1.019 & 0.182 & 0.049 \\
\hline 7 & 0.16 & 1.2 & 4 & 1 & 0.223 & 0.051 & 0.284 & 1.529 & 0.223 & 0.057 \\
\hline 8 & 0.2 & 1.2 & 4 & 1 & 0.223 & 0.051 & 0.284 & 1.529 & 0.223 & 0.052 \\
\hline 9 & 0.144 & 1.0 & 2 & 1 & 0.217 & 0.025 & 0.252 & 1.242 & 0.198 & 0.063 \\
\hline 10 & 0.216 & 1.0 & 2 & 1 & 0.217 & 0.025 & 0.252 & 1.242 & 0.198 & 0.042 \\
\hline 11 & 0.18 & 0.6442 & 2 & 1 & 0.217 & 0.025 & 0.207 & 0.798 & 0.162 & 0.050 \\
\hline 12 & 0.18 & 1.3578 & 2 & 1 & 0.217 & 0.025 & 0.297 & 1.690 & 0.234 & 0.059 \\
\hline 13 & 0.18 & 1.0 & 0 & 1 & 0.212 & 0 & 0.245 & 1.212 & 0.192 & 0.048 \\
\hline 14 & 0.18 & 1.0 & 5.578 & 1 & 0.228 & 0.072 & 0.263 & 1.300 & 0.207 & 0.062 \\
\hline 15 & 0.18 & 1.0 & 2 & 1 & 0.217 & 0.025 & 0.252 & 1.242 & 0.198 & 0.052 \\
\hline 16 & 0.18 & 1.0 & 2 & 1 & 0.217 & 0.025 & 0.252 & 1.242 & 0.198 & 0.052 \\
\hline 17 & 0.18 & 1.0 & 2 & 1 & 0.217 & 0.025 & 0.252 & 1.242 & 0.198 & 0.052 \\
\hline 18 & 0.18 & 1.0 & 2 & 1 & 0.217 & 0.025 & 0.252 & 1.242 & 0.198 & 0.052 \\
\hline
\end{tabular}

Table 2 lists all the calculated real and coded end, central, and axial values of the three investigated parameters.

\subsection{Mixtures}

The 18 combinations were then obtained based on the axial, end, and central values (Table 2). These parameter value combinations are listed in Table 3 .

Mix proportions were determined using the formula M3Q 210. This formula was developed by the Official Material Testing Institute for Construction Industry (Amtliche Materialprüfanstalt für das Bauwesen) (Kusumawardaningsih et al. 2015). It is based on specific mix proportions of fine cementitious and inert materials used for producing UHPC with a cylinder compressive strength of $150 \mathrm{MPa}$. The formula recommends the use of cement and silica fume as cementitious ingredients $(825$ and $175 \mathrm{~kg}$ of cement and SF, respectively, per cubic metre of fresh mix), fine quartz sand ( 0.1 to $0.5 \mathrm{~mm}$ ) of $975 \mathrm{~kg} / \mathrm{m}^{3}$, and quartz flour W12 of 200 $\mathrm{kg} / \mathrm{m}^{3}$. The water content was $200 \mathrm{~kg} / \mathrm{m}^{3}$, corresponding to $\mathrm{w} / \mathrm{c}$ and $\mathrm{W} / \mathrm{B}$ weight ratios of 0.235 and 0.194 , respectively. The microfibre portion was also included in the formula as a flexible percentage of the concrete weight.

Some mixture proportions were adjusted to achieve flexible ingredient proportioning that enables applying current research parameters within the specified ranges.
The proportions of the finest ingredients, namely, silica fume and quartz flour, were maintained, as in the M3Q formula. The total sum of the mass of the binder and fine sand was maintained at $1975 \mathrm{~kg} / \mathrm{m}^{3}$. The sum was then distributed as the total binder and fine sand based on the $\mathrm{s} / \mathrm{b}$ weight ratio of each mixture. The silica fume content was $17.5 \%$ of the total binder, as specified by M3Q 210. The Ns content was determined based on the percentage of Ns per total binder for each mixture. The micro steel fibre content was then obtained to be 157 $\mathrm{kg} / \mathrm{m}^{3}$ based on a fibre volume fraction of $2 \%$ and a steel specific gravity of 7.85 . Table 3 also lists the mix proportions of the constituents expressed in terms of cement weight.

\subsection{Mixing and curing}

Cement and Ns were first placed in a closed plastic bag and vigorously mixed thoroughly for 30 min using a manual rubbing-and-stirring method. Silica fume, fine silica sand, quartz powder, and the cement-Ns blend were dry mixed in a pail using a twin paddle mixer. Dry mixing was continued at a paddle speed of 300 to 400 rpm for a minimum of 15 min until a uniform dry mixture was obtained. Water and half of the superplasticiser (by weight) were added as mixing continued at 400 to $500 \mathrm{rpm}$ paddle speed for approximately $10 \mathrm{~min}$ until spherical wet particles were formed. The remaining quantity of superplasticiser was then added gradually, 
and mixing continued for an additional 5 to $10 \mathrm{~min}$ until a uniform fresh mixture was obtained. Microfibres were added uniformly to the mixture, and an additional $5 \mathrm{~min}$ of mixing was allowed to disperse the fibres in random directions throughout the fresh mixture.

Flow tests were performed, and moulds for the setting time tests were filled with the mixture, both within 5 min after mixing. The $50 \mathrm{~mm}$ cubes for compressive strength tests were cast and vibrated. The cube moulds were then wholly covered with polythene for $24 \mathrm{~h}$ for initial curing at $20 \pm 2^{\circ} \mathrm{C}$. The cube specimens were then heat cured at $90^{\circ} \mathrm{C}$ and $95 \%$ relative humidity $(\mathrm{RH})$ for $48 \mathrm{~h}$ before being cured normally at $20^{\circ} \mathrm{C}$, water fully submerged at a $\mathrm{RH}$ of $100 \%$ for the rest of their designated ages. For early attainment of mechanical properties and dimensional stability, ACI committee report PRC-239R recommends the use of $90^{\circ} \mathrm{C}, 95 \%$ $\mathrm{RH}$ for $48 \mathrm{~h}$ thermal curing regime (Hassan et al. 2016; ACI 2018).

\subsection{Flow test}

The flows of all mixtures were determined according to ASTM C1437 (ASTM 2020a) using a flow table and instruments complying with ASTM C230 (ASTM $2010 \mathrm{~b})$ requirements. The flow test was completed 1 min after the completion of mixing. After a truncated metallic cone was filled with fresh UHPC in two layers through the required tamping, the cone was lifted vertically upward. The table was then dropped 25 times within $15 \mathrm{~s}$. The diameter of the spreading mortar was measured in four directions on the table, and the average was recorded as the spreading flow.

\subsection{HRWR requirements}

HRWR was added gradually, and the flow test was repeated until a flow of 200 to $210 \mathrm{~mm}$ was attained to provide a reasonably workable mix. The final dosage of HRWR associated with the required flow level was recorded as a percentage of the total binder weight to rep- resent the HRWR admixture requirement.

\subsection{Setting time test}

Setting time tests on all 18 mixtures were conducted according to ASTM C807-05 (ASTM 2020b) using an electronic Vicat device with a modified needle apparatus. A stainless steel needle with a diameter of $2 \mathrm{~mm}$ was used, and the total weight of the movable rod, including the needle, was $300 \mathrm{~g}$. The fresh mix sample was poured in a mould with a $76 \mathrm{~mm}$ diameter and a $40 \mathrm{~mm}$ depth. After casting in two layers with tamping, the device was set to zero, with the needle end attached to the surface of the specimen. The rod was allowed to fall under its self weight at fixed time intervals of $5 \mathrm{~min}$ until the needle penetration was less than or equal to $10 \mathrm{~mm}$ from the surface of the sample.

\subsection{Compressive strength test}

Compressive strength tests on $50 \mathrm{~mm}$ cube specimens cast for each of the 18 mixtures were performed. ASTM C109/C109M-11b specifications (ASTM 2010a) were adopted in conducting the tests using a $3000 \mathrm{kN}$ compression test machine. The tests were performed at seven and 28 days. Three cubes were tested at each curing age, and the average value for each age was selected.

\section{Results and discussion}

\subsection{Compressive strength}

Figure 2 shows the variations in the 28 day compressive strengths of the factorial point mixtures with different investigated parameters. The compressive strength of mixtures without Ns particles increased as the $\mathrm{W} / \mathrm{B}$ ratio was decreased from 0.2 to 0.16 . This trend, which applied to both $\mathrm{s} / \mathrm{b}$ ratios of 0.8 and 1.2 , probably occurred because lower water contents resulted in denser microstructures and produced the so called macro-defect-free concrete (Yoo and Banthia 2016). At both $\mathrm{s} / \mathrm{b}$ ratios, a $14 \%$ higher compressive strength was obtained when

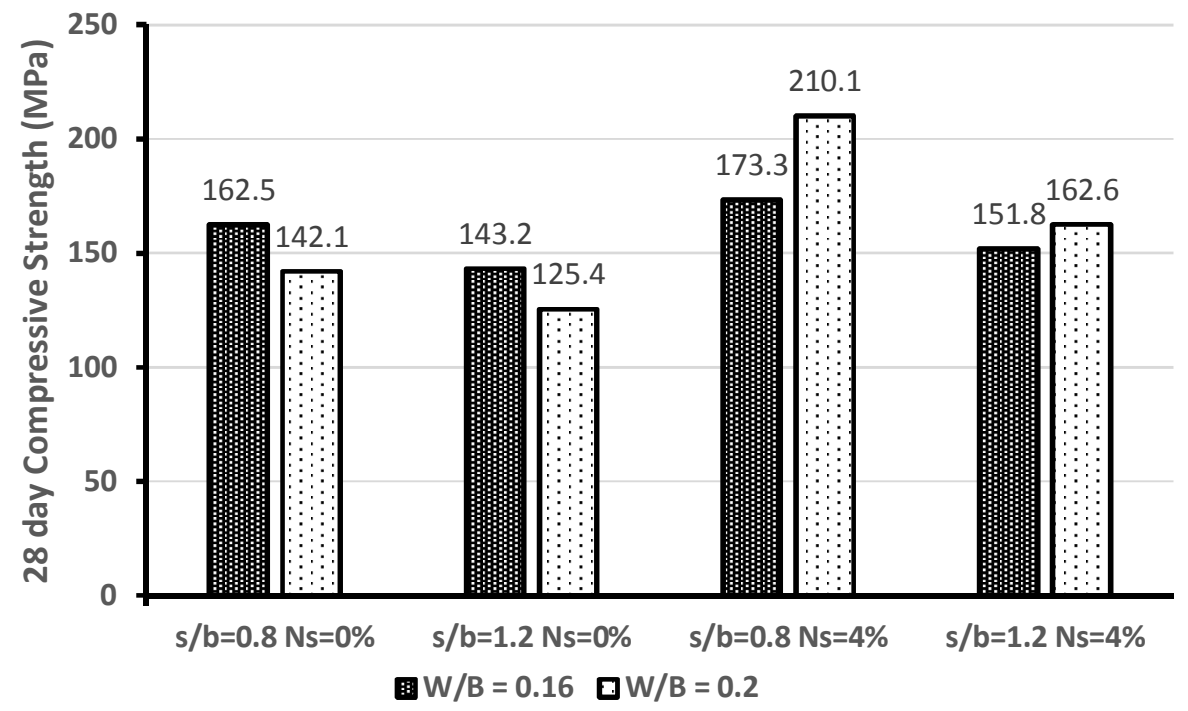

Fig. 2 Effects of W/B ratio, s/b ratio, and Ns content on 28 day compressive strength of factorial mixes. 
the $\mathrm{W} / \mathrm{B}$ ratio was 0.16 , compared to a $0.2 \mathrm{~W} / \mathrm{B}$ ratio.

For mixtures containing $4 \%$ Ns, compressive strengths significantly higher than those of the mixtures without Ns were recorded. A strength enhancement as high as $29.3 \%$ was obtained using the same binder content (with an $\mathrm{s} / \mathrm{b}$ ratio of 0.8 ). Comparable strength values exceeding $150 \mathrm{MPa}$ were achieved with a significantly lower binder content (an s/b ratio of 1.2) when $4 \%$ Ns were incorporated than richer mixtures produced with an $\mathrm{s} / \mathrm{b}$ ratio of 0.8 without Ns. In contrast to the $0 \%$ Ns mixtures, an increase in the $\mathrm{W} / \mathrm{B}$ ratio increased the compressive strength. This behaviour may have occurred because with the increased content of very fine particles associated with the efficient practice of dry mixing, additional pores were filled by the fine particles, and high packing density was attained, improving the mechanical performance. However, finer binder particle contents require more water to lubricate the particles and complete their hydration. A low amount of water increases Ns agglomeration, thus limiting their effectiveness in improving the mechanical behaviour.

For the central and axial point mixtures, the results (Fig. 3) indicated no improvement in the compressive strength was observed when the $\mathrm{W} / \mathrm{B}$ and $\mathrm{s} / \mathrm{b}$ ratios decreased to 0.144 and 0.644 , respectively and the central mixture $(\mathrm{W} / \mathrm{B}=0.18, \mathrm{~s} / \mathrm{b}=1.0, \mathrm{Ns}=2.0 \%)$ revealed a high compressive strength value. The decrease in compressive strength at a low W/B ratio $(0.144)$ can be explained in terms of the water requirements of the high cementitious content in the UHPC mixtures. An adequate degree of hydration of the cementitious components was expected to require a minimum water content, below which decreased compressive strength was anticipated. According to Graybeal (2006), the minimum $\mathrm{W} / \mathrm{B}$ ratio can be as low as 0.12 . However, other researchers have reported that the complete hydration of cement and other supplementary cementitious materials requires a w/c ratio of at least 0.32 (Magureanu et al. 2012). The degree of cement hydration was only $58 \%$ after 28 days of curing because of the low water-binder ratio (Wang 2014).

The axial mixture for the Ns content showed similar behaviour to that of the $\mathrm{W} / \mathrm{B}$ ratio compared to the central mixture. The mixture produced with $5.5 \% \mathrm{Ns}$ exhibited significantly lower compressive strength than the central 2\% Ns mixture. The tendency of the Ns particles to agglomerate when dispersed in high contents may reduce their effective surface area on the one hand and impair their ability to form additional nucleation sites on the other hand. Hydration products precipitate on such nucleation sites, enhancing the hydration rate (ACI 2006).

\subsection{Flow}

Figure 4 shows the flow test results of the factorial mixtures. The flow was significantly influenced by the investigated parameters. The flow generally increased with an increasing $\mathrm{W} / \mathrm{B}$ ratio. When no Ns was added, the flow decreased with an increasing $\mathrm{s} / \mathrm{b}$ ratio. However, at $4 \%$ Ns content, increasing the $\mathrm{s} / \mathrm{b}$ ratio did not affect or slightly increased the recorded flow. A higher water content surrounds the fine particles better and facilitate their movement throughout the mixture. The slight decrease in the flow, owing to an increasing $\mathrm{s} / \mathrm{c}$ ratio, could be attributed to the higher frictional resistance of fine quartz sand than cementitious ingredients. This implied that higher resistance to mixture flowability occurred at higher $\mathrm{s} / \mathrm{b}$ ratios. The marginal effect of the $\mathrm{s} / \mathrm{b}$ ratio on mixture flowability at $4 \% \mathrm{Ns}$ content could indicate that this factor had a negligible influence compared to the Ns content as the predominant factor.

The Ns content had the most significant effect on flowability (Fig. 4). For example, with a 4\% Ns content and a $0.8 \mathrm{~s} / \mathrm{c}$ ratio, the flow decreased by $23.8 \%$ and $28 \%$ for mixtures with $\mathrm{W} / \mathrm{B}$ ratios of 0.16 and 0.2 , respectively. Nanoparticles may absorb relatively high quantities of water, owing to their large surface area, thus reducing the free water available for mixture lubrication. These results are consistent with Yu et al. (2014), who reported a sharp decrease of approximately $33 \%$ in

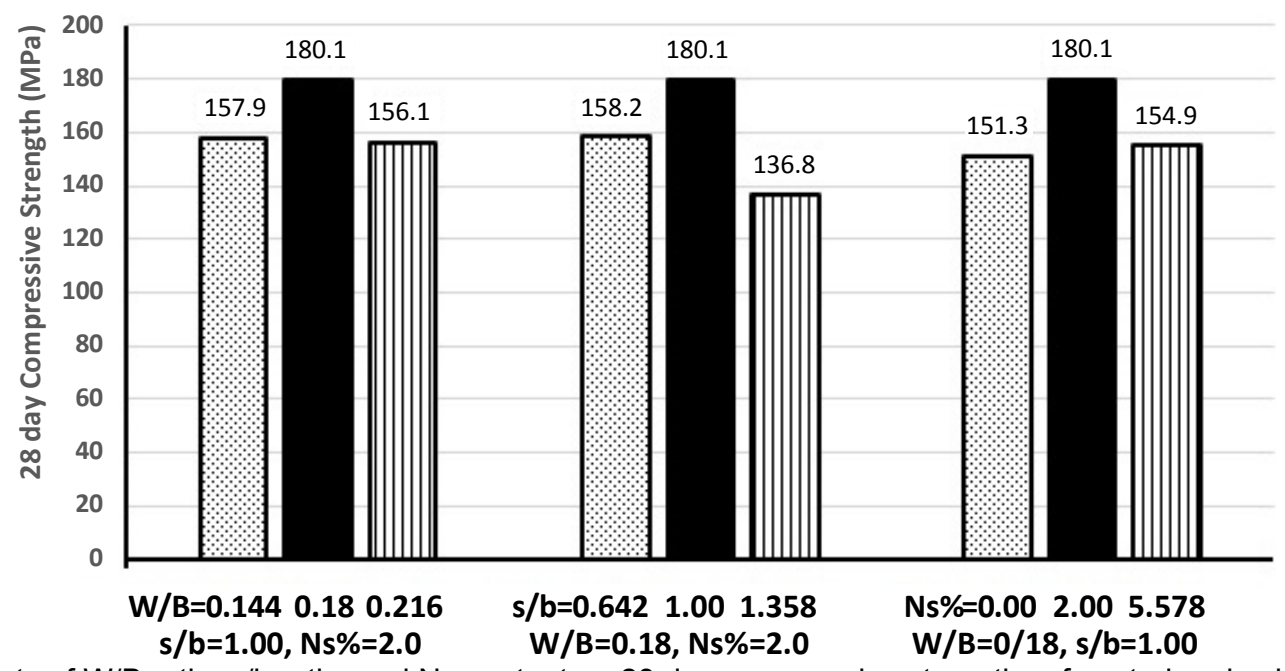

Fig. 3 Effects of W/B ratio, s/b ratio, and Ns content on 28 day compressive strengths of central and axial mixtures. 
the flow when $5 \%$ Ns was added.

\subsection{Setting Time}

Another significant role of the Ns particles in UHPC was the apparent acceleration of the fresh mix setting, as shown in Fig. 5. This favourable influence balanced the slow hardening of the mixes, decreasing their setting times from 3.5 to $7 \mathrm{~h}$ to more practical values of 1 to $2 \mathrm{~h}$. The role of Ns in decreasing the setting time can be explained by their influence, which tends to shorten the dormant period during the early hydration stages (Yu et al. 2014). Mixtures with higher Ns contents typically require higher dosages of HRWR than those with lower Ns contents to maintain practical flowability. Although additional dosages were expected to extend the dormant phase further and significantly retard mixture setting, Ns showed a predominant contrasting effect that counteracted the retarding trend.

\subsection{HRWR requirements}

Figure 6 shows the dosages of HRWR (expressed as percentages of the binder contents) required by the factorial mixtures to attain average flow levels of 200 to $210 \mathrm{~mm}$. The results showed that the HRWR require-

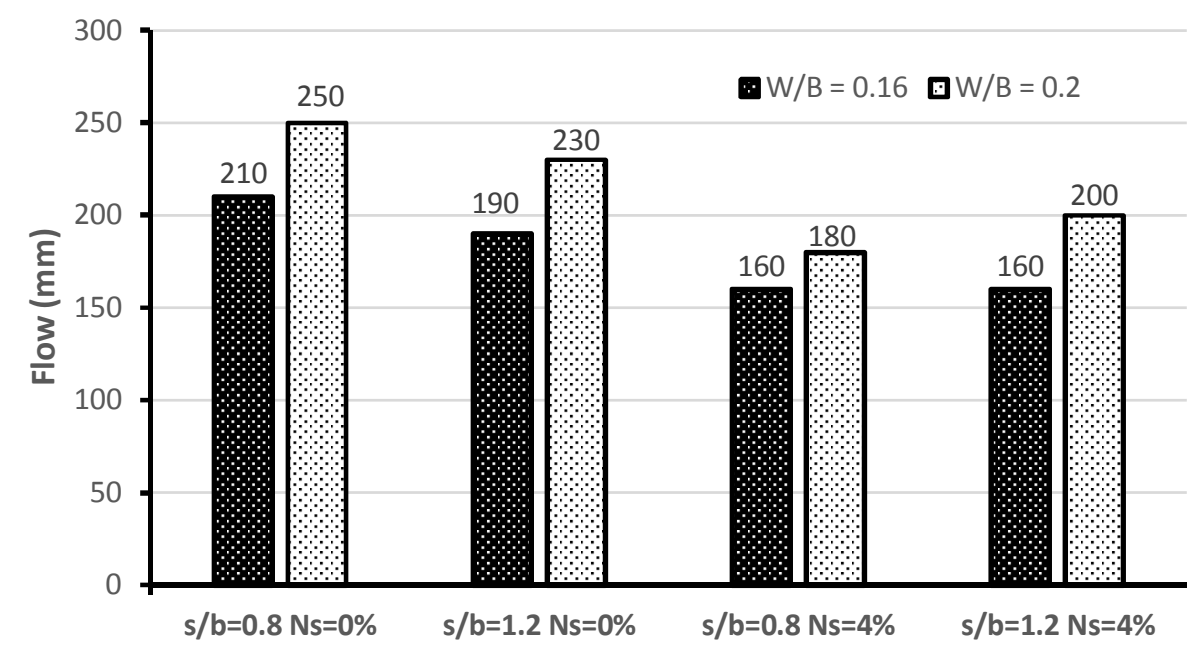

Fig. 4 Flow of factorial mixtures influenced by W/B ratio, s/b ratio, and Ns content.

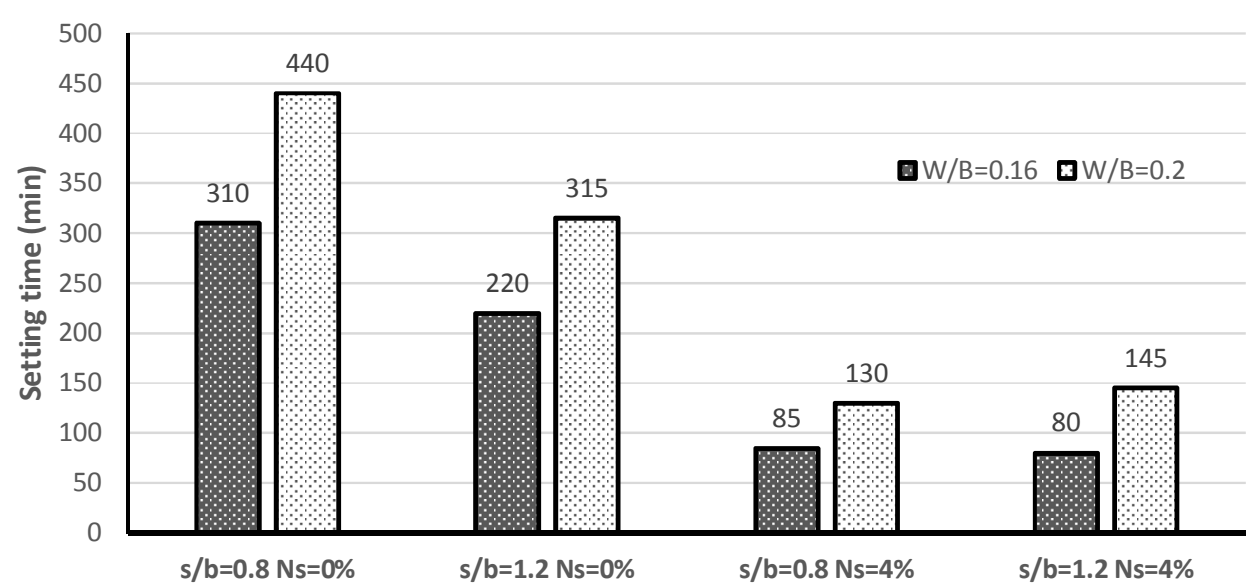

Fig. 5 Fresh UHPC setting time influenced by W/B ratio, s/b ratio, and Ns content.

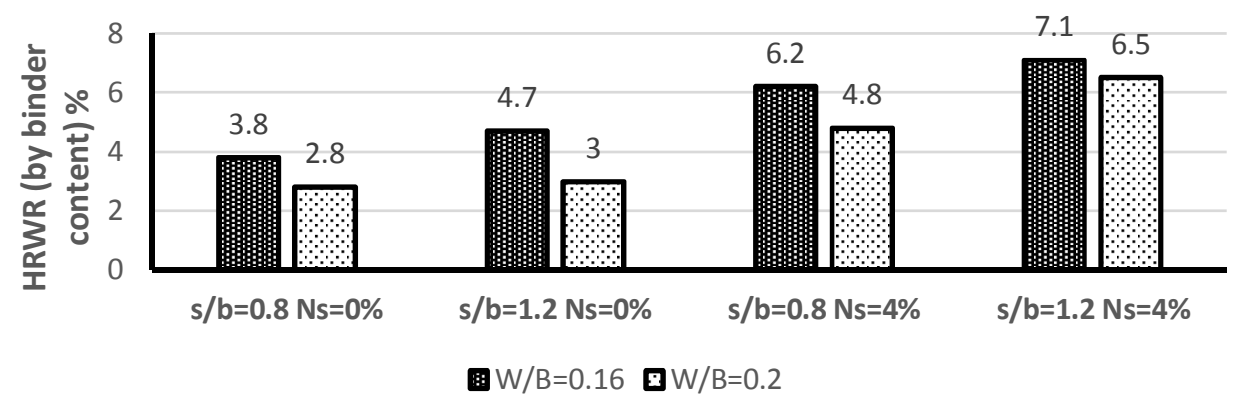

Fig. 6 Effects of W/B ratio, s/b ratio, and Ns content on HRWR required by fresh UHPC mixtures to attain flow of 200 to $210 \mathrm{~mm}$. 
Table 4 Coefficients and p-values of terms in model equations.

\begin{tabular}{|c|c|c|c|c|c|c|}
\hline \multirow[t]{3}{*}{ Term } & \multirow{2}{*}{\multicolumn{2}{|c|}{$\begin{array}{l}28 \text { day compressive strength } \\
\text { Modified by inverse function } \\
\text { transformation } \\
\text { (1/compressive strength) }\end{array}$}} & \multicolumn{2}{|c|}{ Flow } & \multicolumn{2}{|c|}{ Setting time } \\
\hline & & & \multicolumn{4}{|c|}{ No function transformation } \\
\hline & $\mathrm{k}$ & p-value & $\mathrm{k}$ & p-value & $\mathrm{k}$ & p-value \\
\hline Intercept & 0.011117 & $<0.0001$ & 109.16293 & $<0.0001$ & 808.14153 & $<0.0001$ \\
\hline $\mathrm{W} / \mathrm{B}$ & - & & 814.54523 & 0.0002 & -5440.65739 & $<0.0001$ \\
\hline $\mathrm{s} / \mathrm{b}$ & -0.010647 & 0.0005 & -36.97823 & 0.0429 & -255.27990 & 0.0005 \\
\hline Ns & -0.000084 & 0.0002 & -13.26444 & $<0.0001$ & -87.65417 & $<0.0001$ \\
\hline$(\mathrm{W} / \mathrm{B})(\mathrm{s} / \mathrm{b})$ & - & & - & - & - & - \\
\hline$(\mathrm{W} / \mathrm{B}) \mathrm{Ns}$ & -0.003087 & 0.0033 & - & - & -359.37500 & 0.0397 \\
\hline$(\mathrm{s} / \mathrm{b}) \mathrm{Ns}$ & - & & - & - & 70.31250 & 0.0009 \\
\hline$(\mathrm{W} / \mathrm{B})^{2}$ & - & & - & - & 22497.04772 & 0.0583 \\
\hline$(\mathrm{s} / \mathrm{b})^{2}$ & 0.006320 & 0.0075 & - & - & & - \\
\hline $\mathrm{Ns}^{2}$ & 0.000095 & 0.0036 & - & - & 7.54316 & 0.0003 \\
\hline
\end{tabular}

Table 5 ANOVA and fit statistics values of model.

\begin{tabular}{|c|c|c|c|c|c|c|c|}
\hline & $\begin{array}{l}\text { Model } \\
\text { f-value }\end{array}$ & $\begin{array}{l}\text { Model } \\
\text { p-value }\end{array}$ & $\begin{array}{c}\text { Lack-of-fit } \\
\text { p-value }\end{array}$ & $\mathrm{R}^{2}$ & Adjusted $\mathrm{R}^{2}$ & Predicted $\mathrm{R}^{2}$ & Adequate precision \\
\hline $\begin{array}{c}28 \text { day compressive } \\
\text { strength }(\mathrm{MPa})\end{array}$ & 15.10 & $\begin{array}{c}<0.0001 \\
\text { (Significant) }\end{array}$ & $\begin{array}{c}0.1930 \\
\text { (Insignificant) }\end{array}$ & 0.8628 & 0.8057 & 0.5984 & 14.3869 \\
\hline Flow (mm) & 27.64 & $\begin{array}{c}<0.0001 \\
\text { (Significant) }\end{array}$ & $\begin{array}{c}0.1466 \\
\text { (Insignificant) }\end{array}$ & 0.8556 & 0.8246 & 0.7624 & 16.9032 \\
\hline Setting time (min) & 74.09 & $\begin{array}{c}<0.0001 \\
\text { (Significant) }\end{array}$ & $\begin{array}{c}0.1843 \\
\text { (Insignificant) }\end{array}$ & 0.9811 & 0.9678 & 0.9260 & 29.7601 \\
\hline
\end{tabular}

ment consistently increased with decreasing W/B ratio and increasing $\mathrm{s} / \mathrm{b}$ ratio. A higher water content produces more surface wetness of fine ingredients within the fresh mix and, therefore, reduces the amount of HRWR required to achieve sufficient lubrication of the particle surfaces. A high quartz sand content might have enhanced the frictional resistance of the particle surfaces, and high dosages of the superplasticiser were required to overcome the increased resistance. However, the Ns content exhibited the most significant effect on HRWR. Depending on the W/B and $\mathrm{s} / \mathrm{b}$ ratios, $4 \% \mathrm{Ns}$ generally resulted in using $50 \%$ to $110 \%$ extra HRWR to achieve the reference flow.

\subsection{Optimisation}

Based on the discussion above, minimising or maximising a specific parameter does not guarantee positive responses in all cases. For instance, using the maximum Ns content may increase the compressive strength and control the prolonged setting time but may result in low flowability of the mixtures. Therefore, it is essential to:

a. reasonably predict each response based on the influencing parameters;

b. determine the optimum levels of all parameters that can generate the best possible set of responses.

Equations were derived to predict the value of each response (compressive strength, flow, and setting time) based on the results. The general quadratic form of the equation is expressed as follows.

$$
\begin{aligned}
\text { Response }= & k_{1} A+k_{2} B+k_{3} C+k_{4} A B+k_{5} A C \\
& +k_{6} B C+k_{7} A^{2}+k_{8} B^{2}+k_{9} C^{2}
\end{aligned}
$$

The model for each response was then modified to satisfy the conditions of the variance analysis (ANOVA) and fit statistics. The procedure and conditions are similar to those described in the literature (Noordin et al. 2004; Dritsa et al. 2009; Montgomery 2019) and are explained in detail in (State-Ease 2021). The p-value measures the significance of the model. A low p-value indicates a low probability of the null hypothesis (assumption of an insignificant model). Thus, the model is regarded as significant if the p-values of the model and every term are lower than 0.05 (Montgomery 2019). It is also required that the lack of fit is insignificant (that is, its p-value exceeds 0.05 ). Fit statistics were satisfied by maximising the $\mathrm{R}^{2}$ value so that it was close to one. Adequate precision is also an essential parameter determined based on the results, which measures the signal to noise ratio. This implies that the ratio of the predicted values ranges within the average prediction error. A ratio higher than four is desirable for a model used for navigating the design space (Dritsa et al. 2009; StateEase 2021).

Modifications of the equations included one or both of the following measures: (1) function transformation (that is, setting the response under the square root, natural logarithm, or inverse function) and (2) eliminating any of the nine terms in Eq. (2) with high p-values. The coefficients and p-values of the active terms for each response were obtained based on these criteria (Table 4).

\subsubsection{Model verification}

Table 5 lists the f-value, $p$-value, lack-of-fit $p$-value $\mathrm{R}^{2}$, adjusted $R^{2}$, predicted $R^{2}$, and adequate precision values 
for each response. With very low p-values than 0.0001 for all responses, the significance of the model was demonstrated. Lack-of-fit p-values of 0.1466 indicated an insignificant lack of fit, verifying the adequacy of the model (Abellán et al. 2020). Coefficients of determination, $\mathrm{R}^{2}$, of $86.3 \%, 85.6 \%$, and $98.1 \%$ for the 28 day compressive strength, flow, and setting time, respectively, reasonably confirm an acceptable fit between the predicted and actual values of the responses. Furthermore, the adjusted $\mathrm{R}^{2}$ values were somewhat close to the $\mathrm{R}^{2}$ values, indicating that unnecessary terms were not found (Abellán et al. 2020). Moreover, the difference between the predicted and adjusted $\mathrm{R}^{2}$ values for each response did not exceed 0.2. This result reveals that the model fits the data and can be reliably used for interpolation (Montgomery 2019; State-Ease 2021).

\subsubsection{Model checking}

The three dimensional (3D) surfaces [Figs. 7(a), 7(b) and $7(\mathbf{c})$ ] of the interacting effects of the research parameters $(\mathrm{W} / \mathrm{B}$ ratio, $\mathrm{s} / \mathrm{b}$ ratio, and Ns content) on the responses indicated non-linear relationships between these parameters and the 28 day compressive strength, flow, and setting time, as also demonstrated by the model equations. These relationships also reflected the previously discussed interaction effects of these parame- ters in determining the responses.

The model was checked by examining the residuals. The plots of the externally studentised residuals versus the normal probability for the three RSMs (Fig. 8) indicate structureless patterns with the residuals lying reasonably close to and on both sides of the straight line, indicating a normal distribution of errors.

Another method to check the model is shown in Fig. 9. The plots of the predicted values versus actual values of each response demonstrated an appropriate distribution of points close to and on both sides of the straight line, reflecting the relatively high coefficient of regression $\mathrm{R}^{2}$ obtained for each response.

\subsubsection{Optimum solutions output of model}

After validating and verifying the model, optimisation can be achieved by utilising the model. For an optimisation criterion, each response should be typically maximised, minimised, lying within a range, or none. Moreover, other requirements may depend on one or more responses, such as factor weight and importance. The optimisation output represents the parameter values that produce the most favourable results based on the optimisation requirements.

In this study, two optimisation criteria were applied using the proposed model. The major criteria involved
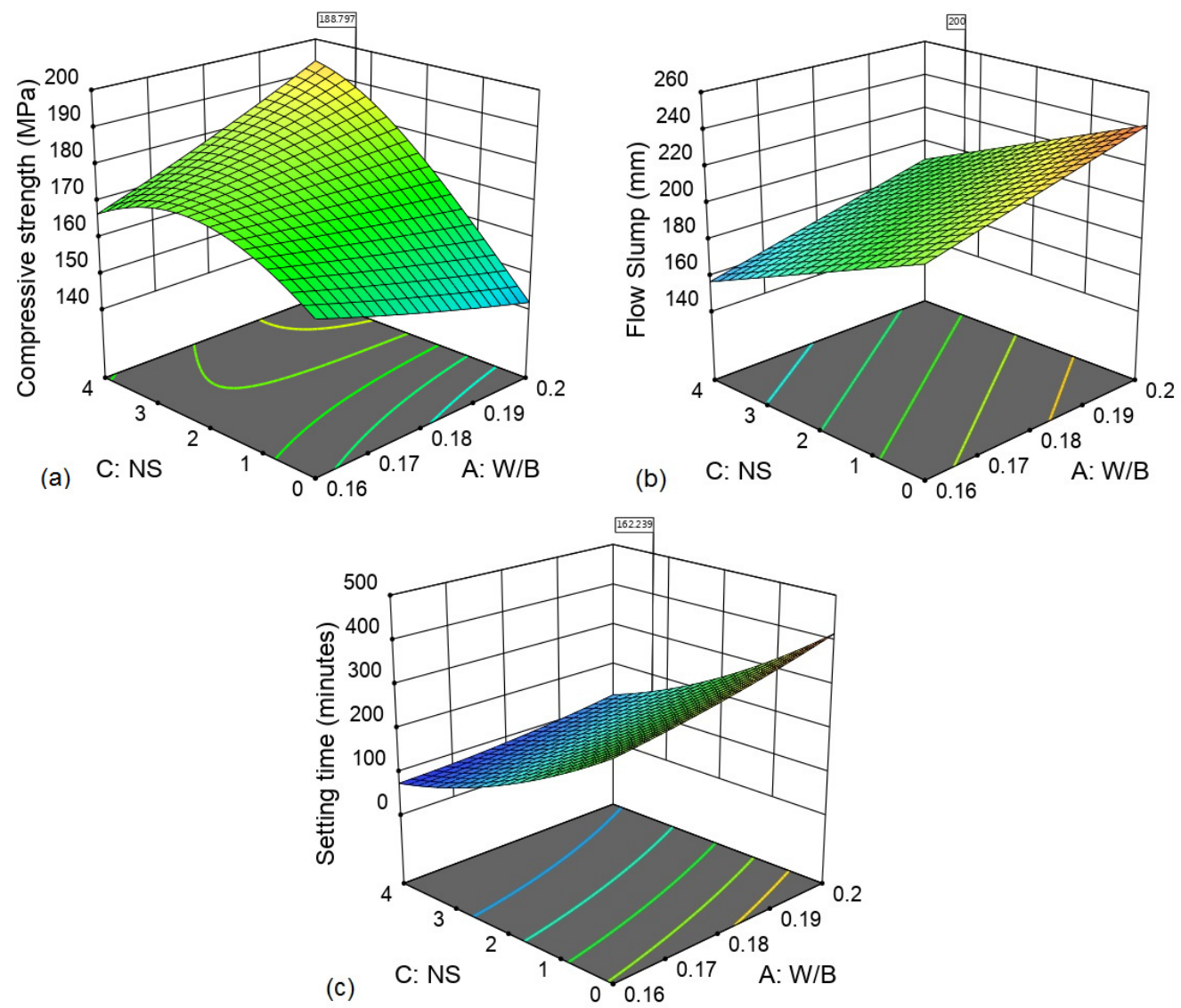

Fig. 7 3D response surface graphs: a) 3D response surface showing effect of W/B ratio and Ns content on 28 day compressive strength $(\mathrm{s} / \mathrm{c}$ ratio $=1.0)$, b) $3 \mathrm{D}$ response surface showing effect of W/B ratio and Ns content on flow $(\mathrm{s} / \mathrm{c}$ ratio $=$ $1.0)$ and c) 3D response surface showing effect of W/B ratio and Ns content on setting time (s/c ratio $=1.0)$. 
(a) maximising the 28 day compressive strength with a minimum value condition (160 MPa), (b) seeking a flow within an acceptable range of 200 to $220 \mathrm{~mm}$, and (c) requiring the setting time to be within 60 to $180 \mathrm{~min}$. At this stage, no condition was applied to the parameters (W/B ratio, s/b ratio, and Ns content), except for their designed ranges.

For the second criterion, two additional conditions were applied to the $\mathrm{s} / \mathrm{b}$ ratio and Ns content. As sand is less expensive and more sustainable than cementitious materials, maximising the $\mathrm{s} / \mathrm{b}$ ratio and minimising the cost-intensive material (Ns content) may reduce the overall cost of UHPC. The other conditions applied to the responses in the first stage were maintained in the second stage, except for decreasing the required minimum compressive strength to $150 \mathrm{MPa}$ and the minimum flow to $180 \mathrm{~mm}$. The two criteria, their conditions, and their outputs are listed in Table 6.

It should be noted that at an Ns content of 3.2\% with $\mathrm{W} / \mathrm{B}$ and $\mathrm{s} / \mathrm{b}$ ratios of 0.2 and 0.8 , respectively, the flowability reduction caused by Ns powder could become small enough to result in a mix flow of $200 \mathrm{~mm}$, along with reasonable 28 day compressive strength of
188.1 MPa and a setting time of $162.2 \mathrm{~min}$. These findings may slightly contradict with Yu's work who reported an optimum Ns content of up to 4\% (Yu et al. 2014). The difference may be attributed to the low cement content used in Yu's work (less than $500 \mathrm{~kg} / \mathrm{m}^{3}$ ). Relatively low levels of cement dosage is expected to result in more porous less densified microstructure that is more likely be improved by the addition of higher contents of the very fine active nano-particles compared to that produced by higher binder content UHPC. Another possible explanation may be related to the mix solids packing density. According to the packing density theory, when very fine particles are added to a less powder content mixture, they fill up more voids resulting in higher packing density. However, with the addition of more dosages of very fine particles a reverse behaviour is expected due to some physical actions that tend to reduce the packing density. When excessive fine particles exist, the particles start to push each other leading to increase the voids content and decrease packing density (Kwan and McKinley 2014). This may suggest that an optimum value of Ns exists that is likely to be lower, the finer original solid particle system is.
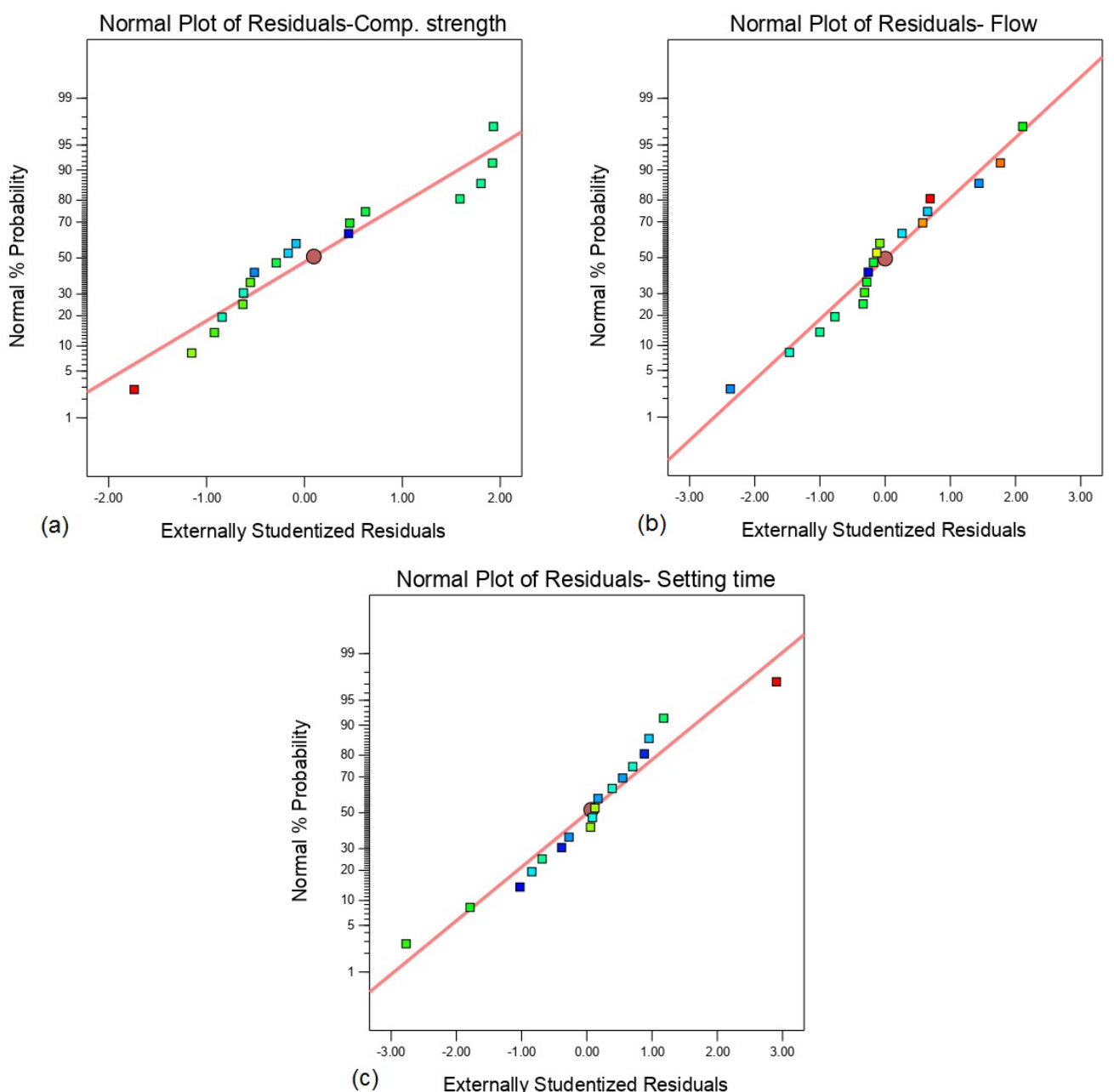

Fig. 8 Plots of residual versus normal probability for each response: a) 28 day compressive strength, b) flow and c) setting time. 
Table 6 Output of optimisation criteria.

\begin{tabular}{|c|c|c|c|c|c|c|}
\hline \multicolumn{7}{|c|}{ First optimisation criterion } \\
\hline \multicolumn{2}{|c|}{ Parameters } & \multicolumn{3}{|c|}{ Responses } & \multirow{2}{*}{ Optimisation output } & \multirow{2}{*}{$\begin{array}{c}\text { Solution } \\
\text { desirability }\end{array}$} \\
\hline & Target & & Target & Range & & \\
\hline $\mathrm{W} / \mathrm{B}$ ratio & In range & $\begin{array}{c}28 \text { day } \\
\text { compressive } \\
\text { strength }\end{array}$ & Maximise & $>160 \mathrm{MPa}$ & \multirow{3}{*}{$\begin{array}{c}\text { 1) } \mathrm{W} / \mathrm{B}=0.2, \mathrm{~s} / \mathrm{b}=0.8, \mathrm{Ns}=3.2 \\
28 \text { day comp. strength }=188.1 \mathrm{MPa} \\
\text { Flow }=200 \mathrm{~mm} \\
\text { Setting time }=162.2 \mathrm{~min} \\
\text { 2) } \mathrm{W} / \mathrm{B}=0.2, \mathrm{~s} / \mathrm{b}=0.94, \mathrm{Ns}=2.8 \\
28 \text { day comp. strength }=182.8 \mathrm{MPa} \\
\text { Flow }=200 \mathrm{~mm} \\
\text { Setting time }=176.6 \mathrm{~min}\end{array}$} & \multirow[t]{2}{*}{0.628} \\
\hline $\mathrm{s} / \mathrm{b}$ ratio & In range & Flow & Maximise & 200 to $220 \mathrm{~mm}$ & & \\
\hline Ns content & In range & Setting time & In range & 60 to $180 \mathrm{~min}$ & & 0.525 \\
\hline \multicolumn{7}{|c|}{ Second optimisation criterion } \\
\hline \multicolumn{2}{|c|}{ Parameters } & \multicolumn{3}{|c|}{ Responses } & \multirow{2}{*}{ Optimisation Output } & \multirow{2}{*}{$\begin{array}{c}\text { Solution } \\
\text { desirability }\end{array}$} \\
\hline & Target & & Target & Range & & \\
\hline $\mathrm{W} / \mathrm{B}$ & In range & $\begin{array}{c}28 \text { day } \\
\text { compressive } \\
\text { strength }\end{array}$ & Maximise & $>150 \mathrm{MPa}$ & \multirow{3}{*}{$\begin{array}{c}\mathrm{W} / \mathrm{B}=0.16, \mathrm{~s} / \mathrm{b}=1.12, \mathrm{Ns}=0.8 \\
28 \text { day comp. strength }=155.9 \mathrm{MPa} \\
\text { Flow }=187 \mathrm{~mm} \\
\text { Setting time }=180 \mathrm{~min}\end{array}$} & \multirow[t]{2}{*}{0.702} \\
\hline $\mathrm{s} / \mathrm{b}$ & Maximize & Flow & In range & $>180 \mathrm{~mm}$ & & \\
\hline Ns & Minimize & Setting time & In range & 60 to $180 \mathrm{~mm}$ & & \\
\hline
\end{tabular}
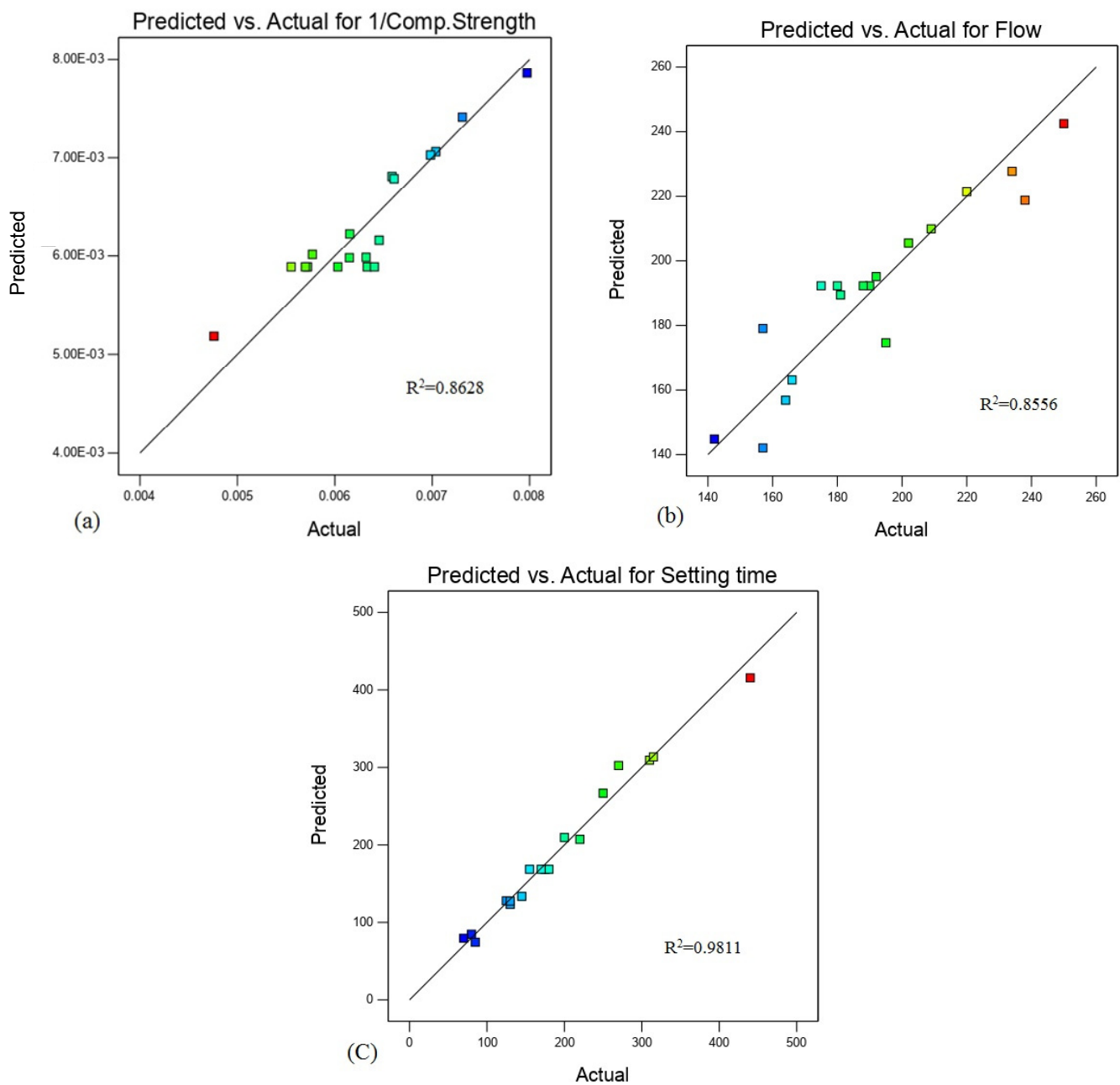

Fig. 9 Plots of predicted versus actual values for each response. a) 28 day compressive strength, b) flow and c) setting time. 
The output of the second optimisation criterion indicated that a high $\mathrm{s} / \mathrm{b}$ ratio of 1.12 with a relatively low Ns content $(0.8 \%)$ at a $\mathrm{W} / \mathrm{B}$ ratio of 0.16 should have exceeded the compressive strength threshold for UHPC with a 28 day compressive strength of $155.9 \mathrm{MPa}$. The same mixture was also expected to achieve a flow of approximately $187 \mathrm{~mm}$ and a setting time of $180 \mathrm{~min}-$ utes.

\section{Conclusions}

In this study, the effects of some critical parameters on the rheological characteristics and compressive strength of UHPC were investigated. Based on these parameters, a statistical model was designed. From the results of the experimental programme and model analysis and outputs, the following conclusions were drawn.

1. The addition of Ns to the UHPC mixtures significantly controlled their prolonged setting times to reasonable levels, with an associated adverse effect on flowability and considerable enhancement of the compressive strength.

2. Mix flowability is consistently related to all research parameters. It decreased significantly with increasing Ns content and consistently increased with increasing $\mathrm{W} / \mathrm{B}$ ratio and decreasing $\mathrm{s} / \mathrm{b}$ ratio.

3. Decreasing the $\mathrm{W} / \mathrm{B}$ ratio, increasing the $\mathrm{s} / \mathrm{b}$ ratio, and/or increasing the Ns content resulted in higher levels of HRWR dosage required to produce reasonably workable mixes. As the most significant parameter, $4 \%$ Ns content resulted in $50 \%$ to $110 \%$ additional HRWR requirements, compared to the reference mixtures without Ns.

4. A statistical model was designed and then statistically verified to optimise the $\mathrm{W} / \mathrm{B}$ ratio, $\mathrm{s} / \mathrm{b}$ ratio, and Ns content to produce UHPC mixtures with the best fresh mix responses (flow and setting time) and the highest 28 day compressive strength. The model also helps predict these responses in terms of these parameters.

5. The optimal sets $(\mathrm{W} / \mathrm{B}=0.2, \mathrm{~s} / \mathrm{b}=0.8$, and $\mathrm{Ns}=$ $3.2 \%)$ and $(\mathrm{W} / \mathrm{B}=0.2, \mathrm{~s} / \mathrm{b}=0.94$, and $\mathrm{Ns}=2.8 \%)$ were predicted to achieve the highest possible 28 day compressive strengths of 188.1 and $182.8 \mathrm{MPa}$, respectively. These two combinations also optimised the other requirements with at least $200 \mathrm{~mm}$ and less than $3 \mathrm{~h}$ of flow and setting time, respectively.

6. Based on the least possible binder and Ns contents, the mix produced using the parameter set $(\mathrm{W} / \mathrm{B}=$ $0.16, \mathrm{~s} / \mathrm{b}=1.12$, and $\mathrm{Ns}=0.8 \%$ ) was statistically proven to exceed the strength threshold limit and exhibit adequate flow and setting time.

7. The optimization also revealed Ns as an effective setting accelerator that may reduce the setting time to as low as 85 min when Ns dosage of $4 \%$ was used. The optimised mix was statistically proven to also ensure acceptable levels of strength and workability.

\section{Acknowledgement}

The authors would like to thank all the Concrete Laboratory staff at the Civil Engineering Department, University of Technology, Baghdad, Iraq, for their support, assistance, and provide facilities. This research did not receive any specific grant from funding agencies in the public, commercial, or non-profit sectors.

\section{References}

AASHTO, (2011). "Standard method of test for time of setting of concrete mixtures by penetration resistance (AASHTO T 197M/T 197 S)." Washington DC: American Association of State Highway and Transportation Officials.

Abellán, J., Fernández, J., Torres, N. and Núñez, A., (2020). "Statistical optimization of ultra-highperformance glass concrete." ACI Materials Journal, $117(1), 243-254$.

ACI-239R, (2018). "Ultra-high-performance concrete: An emerging technology report (ACI Committee Report PRC-239R-18).” Farmington Hills, Michigan: American Concrete Institute.

ACI, (2006). "Guide for the use of silica fume in concrete (ACI Committee Report PRC-234R-06)." Farmington Hills, Michigan: American Concrete Institute.

ASTM, (2010a). "Standard test method for compressive strength of hydraulic cement mortars using 2-in. or 50-mm cube specimens (ASTM C109/C109M-11b)." West Conshohocken, Pennsylvania: ASTM International.

ASTM, (2010b). "Standard specification for flow table for use in tests of hydraulic cement (ASTM C230)." West Conshohocken, Pennsylvania: ASTM International.

ASTM, (2015a). "Standard specification for Portland cement (ASTM-C150/C150M)." West Conshohocken, Pennsylvania: ASTM International.

ASTM, (2015b). "Standard specification for silica fume used in cementitious mixtures (ASTM C1240-15)." West Conshohocken, Pennsylvania: ASTM International.

ASTM, (2019). "Standard test methods for time of setting of hydraulic cement by vicat needle (ASTM C191-19)." West Conshohocken, Pennsylvania: ASTM International.

ASTM, (2020a). "Standard test method for flow of hydraulic cement mortar (ASTM C1437)." West Conshohocken, Pennsylvania: ASTM International.

ASTM, (2020b). "Standard test method for time of setting of hydraulic cement mortar by modified vicat needle (ASTM C807-20)." West Conshohocken, Pennsylvania: ASTM International.

Camiletti, J., Soliman, A. M. and Nehdi, M. L., (2013). "Effect of nano-calcium carbonate on early-age properties of ultra-high-performance concrete." Magazine of Concrete Research, 65(5), 297-307.

de Larrard, F. and Sedran, T., (1994). "Optimization of ultra-high-performance concrete by the use of a packing model." Cement and Concrete Research, 24(6), 997-1009. 
Dobias, D., Pernicova, R. and Mandlik, T., (2016). "Water transport properties and depth of chloride penetration in ultra high performance concrete." Key Engineering Materials, 711, 137-142.

Dritsa, V., Rigas, F., Doulia, D., Avramides, E. J. and Hatzianestis, I., (2009). "Optimization of culture conditions for the biodegradation of Lindane by the polypore fungus Ganoderma australe." Water, Air, and Soil Pollution, 204(1-4), 19-27.

Ehsan, G., Mojtaba, B., Hugo, C. and Eduardo, J., (2015). "Prediction of fresh and hardened state properties of UHPC: Comparative study of statistical mixture design and an artificial neural network model." ASCE Journal of Materials in Civil Engineering, 27(11), Article ID 4015017.

Fehling, E., Schmidt, M., Walraven, J., Leutbecher, T. and Fröhlich, S., (2014). "Ultra-high performance concrete UHPC." Berlin: Ernst \& Sohn.

Fan, L., Meng, W., Teng, L. and Khayat, K. H., (2019). "Effect of steel fibers with galvanized coatings on corrosion of steel bars embedded in UHPC." Composites Part B: Engineering, 177, Article ID 107445.

Ghafari, E., Costa, H., Júlio, E., Portugal, A. and Durães, L., (2014). "The effect of nanosilica addition on flowability, strength and transport properties of ultra high performance concrete." Materials \& Design, 59, $1-9$.

Ghasemi, Y., Emborg, M. and Cwirzen, A., (2019). "Effect of water film thickness on the flow in conventional mortars and concrete." Materials and Structures, 52(3), 62-69.

Ghous, S. M., Ben, W., Amit, J., Ramazan, K., Gozde, O. N., Bora, G., Mina, D. and Abdeldjelil, B., (2018). "Advancements in concrete mix designs: Highperformance and ultrahigh-performance concretes from 1970 to 2016." Journal of Materials in Civil Engineering, 30(3), Article ID 401731000.

Graybeal, B., (2006). “Material property characterization of ultra-high performance concrete (FHWA-HRT-06103)." McLean, Virginia: US Federal Highway Administration.

Graybeal, B. A., (2007). "Compressive behavior of ultra-high-performance fiber-reinforced concrete." ACI Materials Journal, 104(2), 146-152.

Harith, I. K., Hassan, M. S. and Hasan, S. S., (2021). "Liquid nitrogen effect on the fresh concrete properties in hot weathering concrete." Innovative Infrastructure Solutions, 7, Article ID 127-2022.

Hassan, M. S., (2018). "Moisture sensitivity and dimensional stability of carbonated fibre-cement composites." Advances in Cement Research, 30(9), 413-426.

Hassan, M. S., Gorgis, I. N. and Jaber, A. A., (2017). "Fresh and hardened properties of nanosilica and microsilica contained self-consolidating concretes." ARPN Journal of Engineering and Applied Sciences, 17(17), 5140-5150.
Hassan, M. S., Al-azawi, Z. M. and Taher, M. J., (2016). "Complementary effect of heat treatment and steel fibers on mechanical and microstructural properties of high-performance concrete." Arabian Journal for Science and Engineering, 41(10), 3369-3381.

Kusumawardaningsih, Y., Fehling, E. and Ismail, M., (2015). "UHPC compressive strength test specimens: Cylinder or cube?" Procedia Engineering, 125, 10761080.

Kwan, A. K. H. and McKinley, M., (2014). "Effects of limestone fines on water film thickness, paste film thickness and performance of mortar." Powder Technology, 261(13), 33-41.

Magureanu, C., Sosa, I., Negrutiu, C. and Bogdan Heghes, I. S., (2012). "Mechanical properties and durability of ultra-high-performance concrete." $A C I$ Materials Journal, 109(2), 177-184.

Montgomery, D. C., (2019). "Design and analysis of experiments." 10th ed. New York: John Wiley \& Sons Inc.

Náprstek, J., Fischer, C., Pospíšil, S. and Trush, A., (2021). "Modeling of the quasi-periodic galloping response type under combined harmonic and random excitation." Computers \& Structures, 247, Article ID 106478.

Noordin, M. Y., Venkatesh, V. C., Sharif, S., Elting, S. and Abdullah, A., (2004). "Application of response surface methodology in describing the performance of coated carbide tools when turning AISI 1045 steel." Journal of Materials Processing Technology, 145(1), 46-58.

Radhi, M. S., Hassan, M. S. and Gorgis, I. N., (2021). "Carbon fibre-reinforced polymer confinement of corroded circular concrete columns." Journal of Building Engineering, 43, Article ID 102611.

Shafieifar, M., Farzad, M. and Azizinamini, A., (2017). "Experimental and numerical study on mechanical properties of ultra high performance concrete (UHPC)." Construction and Building Materials, 156, 402-411.

Shishegaran, A., Varaee, H., Rabczuk, T. and Shishegaran, G., (2021). "High correlated variables creator machine: Prediction of the compressive strength of concrete." Computers \& Structures, 247, Article ID 106479.

Sidodikromo, E. P., Chen, Z. and Habib, M., (2019). "Review of the cement-based composite ultra-highperformance concrete (UHPC)." The Open Civil Engineering Journal, 13, 147-162.

Soroushian, P., Won, J. P. and Hassan, M. S., (2013). "Sustainable processing of cellulose fiber cement composites." ACI Materials Journal, 110(3), 305-314.

State-Ease, (2021). "Stat-Ease ANOVA [online]." Minneapolis, Minnesota, Stat-Ease Inc. Available from: $<$ https://www.statease.com/docs/v11/navigation/anov a-rsm/> [Accessed 1 August 2021].

Swenty, M. and Graybeal, B., (2013). "Material characterization of field-cast connection grouts (FHWA-HRT-13-042).” McLean, Virginia: US Federal 
Highway Administration.

Wang, X. Y., (2014). "Properties prediction of ultra high performance concrete using blended cement hydration model." Construction and Building Materials, 64, 110.

Xie, T., Fang, C., Mohamad Ali, M. S. and Visintin, P., (2018). "Characterizations of autogenous and drying shrinkage of ultra-high performance concrete (UHPC): An experimental study." Cement and Concrete Composites, 91, 156-173.
Yoo, D. Y. and Banthia, N., (2016). "Mechanical properties of ultra-high-performance fiber-reinforced concrete: A review." Cement and Concrete Composites, 73, 267-280.

Yu, R., Spiesz, P. and Brouwers, H. J. H., (2014). "Effect of nano-silica on the hydration and microstructure development of ultra-high performance concrete (UHPC) with a low binder amount." Construction and Building Materials, 65, 140-150. 